\title{
CONSUMO Y MANEJO DE PLANTAS DURANTE EL PRIMER Y SEGUNDO MILENIO D.C. EN TRES SITIOS ARQUEOLÓGICOS DEL VALLE DE SANTA MARÍA (CATAMARCA-TUCUMÁN,ARGENTINA)
}

\author{
Agustina Longo iD
}

Facultad de Ciencias Naturales y Museo, Universidad Nacional de La Plata, 122 y 60, 1900 La Plata, Buenos Aires, Argentina; agustinalongo@fcnym.unlp.edu.ar (autora corresponsal).

\begin{abstract}
Longo, A. 2021. Plant consumption and management during the first and second millennium AD at three archaeological sites in Santa María valley (Catamarca-Tucumán, Argentina). Darwiniana, nueva serie 9(1): 95-114.

This paper analyses the practices related to the consumption and management of plants in the central-western sector of the Santa María valley (Catamarca-Tucumán) during the first and second millennium AD. For this purpose, we worked with macroremains recovered in the occupation floors and with microremains present in ceramic vessels from the archaeological sites Morro del Fraile, El Carmen 1, and El Carmen 2. A total of 546 carpological macroremains corresponding to seven families, Amaranthaceae, Cactaceae, Cucurbitaceae, Fabaceae, Malvaceae, Poaceae and Solanaceae, and 10 microremains from the families Cucurbitaceae and Poaceae, were identified. The similarities between El Carmen 2 enclosure 2 and Morro del Fraile rock shelter suggest that sites occupied since the first millennium AD would have taken advantage of a greater diversity of plants, which in turn show a great diversity of management practices, in relation to sites occupied from the second millennium A.D., as observed in El Carmen 1 enclosures 1 and 13. The similarities between El Carmen 2 enclosure 2 and Morro del Fraile rock shelter would also indicate a diversity of contexts within the second millennium $\mathrm{AD}$, with spaces that show a lower diversity of plants (El Carmen 1 enclosures 1 and 13) and spaces that, during the second millennium AD, exhibit practices that refer to those known for the villages of the first millennium AD (Morro del Fraile rock shelter), such as the consumption of a great diversity of wild, weedy and domesticated plants, with a predominance of Trichocereus and various Amaranthaceae.
\end{abstract}

Keywords. Archaeobotany; first and second millennium A.D.; macroremains; microremains; residential spaces; Santa Maria valley.

Resumen. Longo, A. 2021. Consumo y manejo de plantas durante el primer y segundo milenio d.C. en tres sitios arqueológicos del valle de Santa María (Catamarca-Tucumán, Argentina). Darwiniana, nueva serie 9(1): 95-114.

En el presente trabajo se analizan las prácticas vinculadas al consumo y manejo de plantas en el sector centro-occidental del valle de Santa María (Catamarca-Tucumán) durante el primer y segundo milenio d.C. Para ello se trabajó con macrorrestos recuperados en los pisos de ocupación y con microrrestos presentes en vasijas cerámicas de los sitios arqueológicos Morro del Fraile, El Carmen 1 y El Carmen 2. Se identificaron 546 carporrestos correspondientes a siete familias, Amaranthaceae, Cactaceae, Cucurbitaceae, Fabaceae, Malvaceae, Poaceae y Solanaceae, y 10 microrrestos que pertenecen a las familias Cucurbitaceae y Poaceae. Las semejanzas entre el recinto 2 de El Carmen 2 y el alero de Morro del Fraile sugieren que en los sitios que presentan ocupaciones desde el primer milenio d.C. se habrían aprovechado una mayor diversidad de plantas, que muestran, a su vez, una gran diversidad de prácticas de manejo, en relación con los sitios ocupados a partir del segundo milenio d.C., como se observó en los recintos 1 y 13 de El Carmen 1. 
Las semejanzas entre el recinto 2 de El Carmen 2 y el alero de Morro del Fraile indicarían también una diversidad de contextos al interior del segundo milenio d.C., con espacios que muestran una menor diversidad de plantas (recintos 1 y 13 de El Carmen 1) y espacios que, durante el segundo milenio d.C., exhiben prácticas que remiten a aquellas conocidas para las aldeas del primer milenio d.C. (alero de Morro del Fraile), como el consumo de gran diversidad de plantas silvestres, malezas y domesticadas, con predominio de Trichocereus y de diversas Amaranthaceae.

Palabras claves. Arqueobotánica; espacios residenciales; macrorrestos; microrrestos; primer y segundo milenio d.C.; valle de Santa María.

\section{INTRODUCCIÓN}

El valle de Santa María, con una altitud de entre 1600 y 2000 m s.m., forma parte del área Valliserrana del noroeste argentino y atraviesa en sentido nortesur las actuales provincias de Tucumán y Catamarca (Argentina). Surcado por el río Santa María, su colector principal, limita al oeste con la sierra del Cajón y al este con el cordón montañoso sierra del AconquijaCumbres Calchaquíes, que lo comunican con el valle delCajón hacia la punay con el abra del Infiernillohacia las yungas, respectivamente (Ruiz Huidobro, 1972). De acuerdo con las investigaciones que dan cuenta de su historia en tiempos prehispánicos, el valle de Santa María ha sido escenario, al menos desde inicios de la era cristiana, de aldeas sedentarias con unidades domésticas dispuestas en terrenos propicios tanto para las actividades agrícolas como pastoriles, que a fines del primer milenio d.C. dieron lugar a los poblados conglomerados característicos del segundo milenio d.C. (Scattolin, 2006). La aparición de concentraciones edilicias en varios puntos elevados del paisaje, alrededor del 1000 d.C., dio lugar al reconocimiento de un patrón definido por la metáfora de chakras y pukaras que llevó a pensar en cambios demográficos y productivos, quizás vinculados a una intensificación agrícola (Tarragó, 2000). Los sitios arqueológicos El Carmen 1 (EC1), El Carmen 2 (EC2) y Morro del Fraile (MF), con evidencias de ocupación residencial, y características de emplazamiento, productivas y cronológicas particulares, dan cuenta de los diversos modos de vida y procesos sociales conocidos para el lapso temporal del primer al segundo milenio d.C. (Fig. 1A). EC1 y MF fueron definidos como centros poblados (Nastri, 1997-1998), con una forma particular de organizar el espacio dada por la monumentalización del espacio residencial (Coll Moritan, 2018a). EC1 representa un típico caso de los pukara (sensu Tarragó, 2011) conocidos para el área Surandina durante el segundo milenio d.C., mientras que MF presenta características particulares que lo asemejan a los poblados de fines del primer milenio d.C. (e.g. Morro de Las Espinillas [Scattolin, 2003]). EC2, por su parte, presenta unidades residenciales cercanas a estructuras agrícolas, así como líneas de piedras que podrían constituir los cimientos de antiguas viviendas como ocurre en las ocupaciones del primer milenio d.C. en el valle (Nastri et al., 2009).

Con la reciente incorporación de técnicas de recuperación de restos vegetales en excavaciones arqueológicas (Oliszewski, 1997; Arreguez et al., 2015), se profundizaron los estudios acerca de las interacciones que los habitantes han tenido con las plantas a lo largo del tiempo. Sin embargo, aún son escasos los estudios realizados en el valle de Santa María, siendo ausentes los análisis de microrrestos en vasijas. Los análisis arqueobotánicos realizados en unidades residenciales de los sitios Loma Alta y Soria 2 dieron a conocer actividades de consumo y procesamiento de plantas realizadas en los patios de las viviendas, así como de prácticas de recolección, tolerancia y cultivo vinculadas al modo de vida aldeano del primer milenio d.C. (Pochettino \& Scattolin, 1991; Petrucci \& Spano, 2019). Estudios específicos en Rincón Chico analizaron el consumo y procesamiento de plantas en el marco de la organización interna del poblado, y sugirieron una distribución desigual de las actividades realizadas en los sectores bajo y alto de este poblado característico del segundo milenio d.C. (Petrucci \& Tarragó, 2015; Petrucci \& Tarragó, 2019). Recientes investigaciones diacrónicas realizadas en el valle de Santa María sugieren la existencia de cambios y continuidades en el lapso temporal analizado. Los estudios, realizados en los sitios Soria 2 y Rincón Chico, muestran un predominio del consumo de malezas (Trichocereus: "cardón") y una gran diversidad 

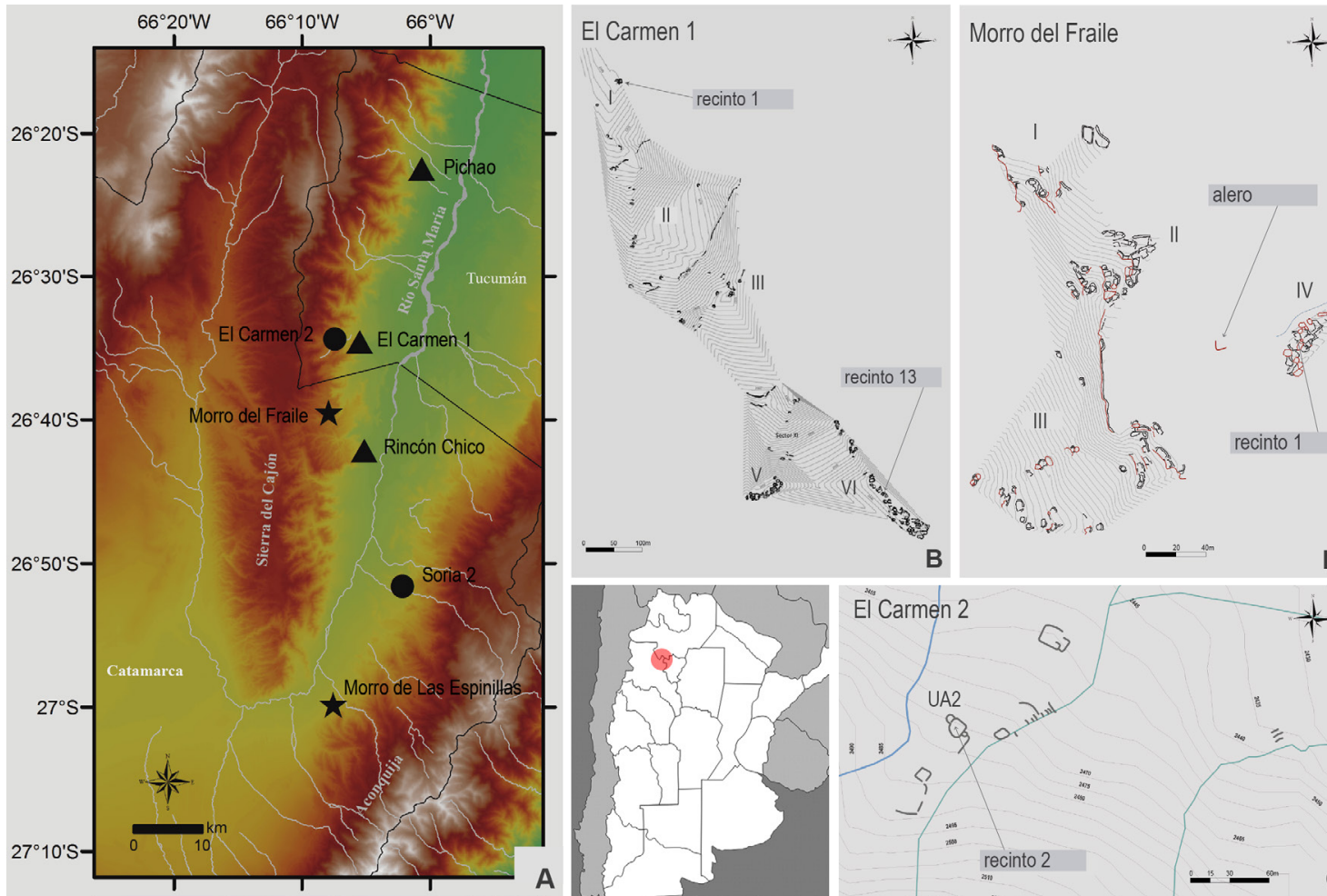

Fig. 1. Sitios arqueológicos del valle de Santa María (Catamarca-Tucumán, Argentina). A, sitios del primer y segundo milenio d.C. analizados. B. Plano de El Carmen 1 (modificado de Coll Moritan et al., 2015). C. Croquis de El Carmen 2 (modificado de Longo, 2020). D. Plano de Morro del Fraile (modificado de Coll Moritan, 2018b). Figura en color en la versión en línea http://www.ojs.darwin.edu.ar/index.php/darwiniana/article/view/939/1211

de grados de asociación entre plantas y humanos durante el primer milenio d.C. en comparación al segundo milenio d.C., donde habrían predominado en proporciones semejantes las plantas silvestres (Prosopis: "algarrobo") y los cultivos domesticados (Zea mays: "maíz"); al mismo tiempo que diversos granos de Chenopodium (Amaranthaceae) se habrían consumido de manera continua a lo largo de estos dos milenios, con representación de especies silvestres, malezas y domesticadas (Petrucci et al., 2018).

El objetivo del presente trabajo es contribuir a la comprensión de las trayectorias locales en el consumo y manejo de plantas en el sector centrooccidental del valle de Santa María (CatamarcaTucumán, Argentina) durante el primer y segundo milenio d.C., a partir del análisis arqueobotánico de macrorrestos recuperados en pisos de ocupación y de microrrestos presentes en vasijas cerámicas de los sitios arqueológicos MF, EC1 y EC2.

\section{MATERIALES Y MÉTODOS}

\section{Sitios arqueológicos estudiados}

El sitio EC1 (Fig.1B) ocupa cerca de 60 ha, ubicado al pie de la sierra del Cajón; sobre la cima y laderas de un cerro se disponen un conjunto de 350 elementos arquitectónicos que presentan una organización interna sectorizada con áreas residenciales, agrícolas y defensivas. Se destaca la presencia de 13 morteros ubicados en los sectores bajos del poblado, asociados a áreas agrícolas o defensivas; ninguno de ellos está ubicado en los sectores residenciales emplazados en las cimas de la sierra. Los estudios realizados indican una ocupación entre 1222-1405 cal d.C. $(p=95,4)$ (Coll Moritan et al., 2015; Cantarelli, 2019) (Tabla 1).

El sitio EC2 (Fig. 1C) ocupa cerca de 6 ha, ubicado al interior de la quebrada del Carmen, a unos $2 \mathrm{~km}$ al oeste de EC1; adyacentes al río, sobre la ladera sur de la quebrada, se disponen un conjunto 
Tabla 1. Características de las muestras analizadas en los sitios Morro del Fraile (MF), El Carmen 1 (EC1) y El Carmen 2 (EC2). Fechados radiocarbónicos calibrados con el programa OxCal v4.3.2 Bronk Ramsey (2017), Curva SHCal13 Hogg et al. (2013).

\begin{tabular}{|c|c|c|c|c|c|c|c|c|c|c|c|}
\hline \multirow[b]{2}{*}{ Sitio } & \multirow[b]{2}{*}{ Sector } & \multirow[b]{2}{*}{ Estructura } & \multirow{2}{*}{$\begin{array}{c}\text { Porcentaje } \\
\text { excavado }\end{array}$} & \multicolumn{5}{|c|}{ Fechados } & \multicolumn{2}{|c|}{ Sedimento } & \multirow{2}{*}{$\begin{array}{c}\text { Tiestos } \\
\mathrm{n}\end{array}$} \\
\hline & & & & Código & Material & Evento & $\begin{array}{c}\text { Edad C } C^{14} \\
\text { AP }\end{array}$ & $\begin{array}{c}\mathrm{Cal} 2 \sigma \\
(95,4 \%)\end{array}$ & Litros & Procedencia & \\
\hline \multirow[t]{4}{*}{ MF } & \multirow[t]{4}{*}{ III } & \multirow[t]{4}{*}{ Alero } & \multirow[t]{4}{*}{$31 \%$} & LP2039 & Carbón & Fogón & $1150 \pm 70$ & 766-1134 d.C. & \multirow[t]{4}{*}{6,85} & \multirow{4}{*}{ piso y fogón } & \multirow{4}{*}{ 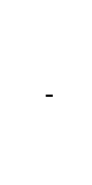 } \\
\hline & & & & LP2488 & Carbón & - & $930 \pm 50$ & 1029-1260 d.C. & & & \\
\hline & & & & LP2061 & Carbón & Piso & $900 \pm 80$ & 1025-1284 d.C. & & & \\
\hline & & & & LP2834 & Carbón & $\begin{array}{l}\text { Inicio } \\
\text { Piso }\end{array}$ & $830 \pm 60$ & 1053-1380 d.C. & & & \\
\hline \multirow[t]{2}{*}{ MF } & \multirow[t]{2}{*}{ IV } & \multirow[t]{2}{*}{ Recinto 1} & \multirow[t]{2}{*}{$30,4 \%$} & AA88804 & Carbón & Piso & $882 \pm 36$ & 1071-1274 d.C. & \multirow[t]{2}{*}{3,75} & \multirow{2}{*}{$\begin{array}{l}\text { piso y lentes } \\
\text { de ceniza }\end{array}$} & \multirow[b]{2}{*}{-} \\
\hline & & & & LP2476 & Carbón & Piso & $710 \pm 60$ & 1230-1405 d.C. & & & \\
\hline \multirow[t]{3}{*}{$\mathrm{EC} 1$} & I & Recinto 1 & $17,4 \%$ & LP2846 & Carbón & Fogón & $750 \pm 50$ & 1222-1391 d.C. & \multirow[t]{2}{*}{4,45} & \multirow{2}{*}{ piso y fogón } & \multirow[t]{2}{*}{2} \\
\hline & & & & LP2865 & Carbón & Fogón & $670 \pm 50$ & 1285-1405 d.C. & & & \\
\hline & VI & Recinto 13 & $50,6 \%$ & LP2876 & Carbón & $\begin{array}{l}\text { Hoyo } \\
\text { poste }\end{array}$ & $680 \pm 50$ & 1282-1403 d.C. & 9,05 & piso y fogón & - \\
\hline \multirow[t]{3}{*}{$\mathrm{EC} 2$} & - & Recinto 2 & $5 \%$ & AA111474 & Hueso & Piso & $1567 \pm 28$ & 436-602 d.C. & 23,5 & \multirow{3}{*}{$\begin{array}{l}\text { piso y } \\
\text { probable } \\
\text { fogón }\end{array}$} & \multirow[t]{3}{*}{4} \\
\hline & & & & AA112039 & Hueso & Piso & $383 \pm 20$ & 1463-1627 d.C. & & & \\
\hline & & & & AA112040 & Hueso & Piso & $382 \pm 20$ & 1464-1627 d.C. & & & \\
\hline
\end{tabular}

de 32 elementos arquitectónicos que conforman unidades residenciales, agrícolas, unidades con probable funcionalidad agrícola/ganadera, así como 2 morteros simples. Las evidencias de la cerámica de superficie, con estilos característicos del primer y segundo milenio d.C., sugieren una ocupación durante un lapso temporal prolongado (Nastri et al., 2009; Longo \& Nastri, 2018). Los resultados de los fechados realizados en el recinto 2 indican que habría sido ocupado en dos momentos distantes, uno entre 436-602 cal d.C., y otro mil años después, entre 14631627 d.C. cal d.C. $(\mathrm{p}=95,4)$ (Longo, 2020) (Tabla 1).

El sitio MF (Fig. 1D) ocupa 3,8 ha, ubicado al interior de la sierra del Cajón; en las laderas escarpadas de un morro (sectores I, II y III) y en el fondo de la quebrada (sector IV) se disponen cerca de 100 elementos arquitectónicos y al pie del morro a orillas del curso de agua, un pequeño alero de $20 \mathrm{~m}^{2}$ (sector III) con evidencias de ocupación humana. Está compuesto principalmente por unidades residenciales, excepto por dos recintos de mayor tamaño con funcionalidad ganadera en el sector I; en el sector IV se destaca la presencia de dos morteros inmóviles, uno simple y otro múltiple con 18 oquedades, asociados a los recintos habitacionales (Coll Moritan, 2017). Los estudios realizados proponen una ocupación desigual del poblado a lo largo del tiempo, con una ocupación del recinto 10 del sector I entre 684-1035 cal d.C., del recinto 1 del sector IV entre 1071-1405 cal d.C. y del alero del sector III, de manera contemporánea al resto del sitio, entre 766-1380 cal d.C. $(p=95,4)$ (Nastri, 1997-1998; Nastri et al., 2010; Nastri et al., 2012; Coll Moritan, 2018b) (Tabla 1). La estrategia defensiva basada en la ocultación y, por lo tanto, la no intervisibilidad con otros poblados, así como la ausencia de espacios públicos construidos, son algunas de las características que lo alejan de los típicos poblados pukara conocidos para el valle de Santa María. Nastri et al. (2012) plantean la posibilidad de un uso estacional vinculado con actividades pastoriles, de acuerdo con la cual MF podría haber funcionado como espacio residencial desde donde se trasladarían a los puestos ganaderos cercanos, como El Trébol 1 y 2.

\section{Muestras analizadas}

Las muestras analizadas provienen de cuatro contextos habitados en momentos cronológicos particulares que permitirán realizar el análisis diacrónico propuesto: el alero del sector III de MF (MF.A), el recinto 1 del sector IV de MF (MF.R1), los recintos 1 del sector I y 13 del sector IV de EC1 (EC1.R1 y EC1.R13, respectivamente) y el recinto 2 de EC2 (EC2.R2) (Fig. 1B-D, Tabla 1). El análisis arqueobotánico comprende carporrestos (semillas y frutos) y microrrestos procedentes de semillas, frutos y órganos de almacenamiento subterráneos (granos de almidón y fitolitos). 
Macrorrestos vegetales. Se analizaron muestras de sedimento de los pisos de ocupación, así como muestras puntuales de los fogones de cada contexto de análisis (Tabla 1). El método utilizado para la recuperación de macrorrestos fue la flotación manual y tamizado en seco utilizando mallas finas de $1 \mathrm{y}$ 0,48 mm (Oliszewski, 1997; Arreguez et al., 2015). En EC2.R2 se tomaron muestras desde el nivel 4 (1 litro cada 25 litros de sedimento por cada unidad estratigráfica y 1 litro por cada nivel artificial) y se utilizólatécnicadeflotaciónmanual.EnEC1.R1,EC1. R13, MF.A y MF.R1 se estudiaron muestras halladas en excavaciones previas que fueron aprovechadas en este trabajo para la recuperación de restos vegetales mediante tamizado en seco. En este sentido, se analizaron 80 muestras de sedimento que suman 47,6 litros, de las cuales 19 corresponden a MF.A (6,85 litros), 10 a MF.R1 (3,75 litros), 27 a EC1.R1 (4,45 litros) y EC1.R13 (9,05 litros) y 24 a EC2.R2 (23,5 litros). Debido a que las muestras presentan distintos volúmenes de sedimento $\left(100-1400 \mathrm{~cm}^{3}\right)$, para los análisis comparativos se las estandarizó a través de la medida de densidad, considerando la cantidad absoluta de restos por litro de sedimento analizado (Miller, 1988; Popper, 1988). A fin de recuperar los restos carpológicos, se observó bajo lupa la fracción liviana de las muestras de flotación y todo el material recuperado del tamizado en seco. Para asegurarnos de que los restos encontrados se correspondan con aquellos utilizados por las sociedades bajo estudio, se consideraron únicamente carporrestos en estado carbonizado. Cuando los frutos y/o semillas fueran de color negro en estado seco, e.g. Trichocereus sp., se realizó un corte transversal para corroborar que estuvieran carbonizados. La identificación taxonómica se realizó a partir de la comparación de los restos arqueológicos encontrados con una colección de frutos y semillas carbonizados, material del herbario del Laboratorio 129 (Facultad de Ciencias Naturales y Museo, Universidad Nacional de La Plata) y con la consulta del Catálogo de Plantas Vasculares del Cono Sur (Zuloaga et al., 2019) y de la bibliografía específica de la familia correspondiente, i.e. Amaranthaceae (Planchuelo, 1975), Cactaceae (Kiesling, 1978), Cucurbitaceae (Lema et al., 2008; Pozner, 2010), Fabaceae (Burkart, 1949, 1976), Malvaceae (MuñozSchick, 1995), Solanaceae (Lema, 2009), Poaceae (Parodi, 1959; Abiusso \& Cámara Hernández 1974).
Se utilizó la nomenclatura botánica de la base de datos Trópicos (2021). Se registraron un conjunto de variables cualitativas y cuantitativas (e.g. tamaño, forma, posición del hilo y la micrópila, textura de la cubierta seminal), que fueron observadas en lupa a bajos aumentos (20x-40x), prestando especial atención a los caracteres diagnósticos que permitieran reconocer distintos grados de asociación ser humano-planta (especies silvestres, domesticadas, malezas), como una vía que permita acercarnos a las prácticas de manejo que habrían estado involucradas en su obtención (Lema, 2009; Petrucci et al., 2018; Petrucci \& Spano, 2019). Se consideraron diversas prácticas, además de cultivo y recolección, como tolerancia y fomento (Casas, 2001).

Microrrestos vegetales. Se analizaron seis muestras de fragmentos cerámicos recuperados en lospisosdeocupacióndeEC1.R1yEC2.R2(Tabla1), que fueron separadas en papel aluminio durante las excavaciones. Se muestrearon superficies internas de ollas que presentan hollín, así como irregularidades o huecos en superficies internas de ollas y en decoraciones modeladas en bordes de pucos (Pazzarelli, 2011). Se siguió el protocolo de extracción directa de residuos por raspado en seco (Lema et al., 2015). La extracción se realizó en un ambiente cerrado y esterilizado, utilizando un pincel para cada fragmento y se tomaron muestras de igual volumen. Se consideraron dos tipos de microrrestos susceptibles de ser encontrados en semillas, frutos y órganos de almacenamiento subterráneos: granos de almidón y fitolitos. Ambos microrrestos son apreciables a medianos aumentos (200x-400x). Se utilizó microscopio Leica de luz transmitida normal y polarizada perteneciente al Laboratorio 129 (FCNyM, UNLP). Las muestras fueron montadas en aceite de inmersión, medio que no fija los microrrestos y permite su rotación para observarlos en sus tres dimensiones. La caracterización de los microrrestos se realizó considerando atributos cualitativos y cuantitativos y para su descripción se utilizó la terminología específica (e.g. Madella et al., 2005; Patterer et al., 2011; Pagán Jiménez, 2015). Para la identificación de los microrrestos de cada planta se consultó Korstanje \& Babot (2007) y bibliografía pertinente para cada taxón analizado. 
Tabla 2. Cantidad absoluta (n) y densidad por litro de sedimento (d/l) de macrorrestos recuperados en los sitios Morro del Fraile (MF), El Carmen 1 (EC1) y El Carmen 2 (EC2). S, sector; R, recinto.

\begin{tabular}{|c|c|c|c|c|c|c|c|c|c|c|c|c|c|c|}
\hline & \multirow[t]{3}{*}{ Taxón } & \multirow{3}{*}{$\begin{array}{l}\text { Grado de } \\
\text { asociación }\end{array}$} & \multirow{3}{*}{$\begin{array}{l}\text { Órgano } \\
\text { recuperado }\end{array}$} & \multirow{2}{*}{\multicolumn{2}{|c|}{$\begin{array}{c}\text { MF } \\
\text { SIII } \\
\text { Alero }\end{array}$}} & \multirow{2}{*}{\multicolumn{2}{|c|}{$\begin{array}{l}\text { MF } \\
\text { SIV } \\
\text { R1 }\end{array}$}} & \multirow{2}{*}{\multicolumn{2}{|c|}{$\begin{array}{c}\text { EC1 } \\
\text { SI } \\
\text { R1 }\end{array}$}} & \multirow{2}{*}{\multicolumn{2}{|c|}{$\begin{array}{l}\text { SVI } \\
\text { R13 }\end{array}$}} & \multirow{2}{*}{\multicolumn{2}{|c|}{$\begin{array}{c}\text { EC2 } \\
- \\
\text { R2 }\end{array}$}} & \multirow[t]{2}{*}{ Total } \\
\hline & & & & & & & & & & & & & & \\
\hline & & & & $\mathrm{n}$ & $\mathrm{d} / 1$ & $\mathrm{n}$ & $\mathrm{d} / 1$ & $\mathrm{n}$ & $\mathrm{d} / 1$ & $\mathrm{n}$ & $\mathrm{d} / 1$ & $\mathrm{n}$ & $\mathrm{d} / 1$ & $\mathrm{n}$ \\
\hline \multirow[t]{3}{*}{ Amaranthaceae } & $\begin{array}{l}\text { Chenopodium quinoa } \\
\text { Willd. }\end{array}$ & Indeterminado & $\begin{array}{l}\text { Grano } \\
\text { (fruto) }\end{array}$ & 2 & 0,3 & - & - & - & - & 279 & 30,8 & 3 & 0,1 & 314 \\
\hline & Chenopodium L. & Indeterminado & $\begin{array}{c}\text { Grano } \\
\text { (tegumento) }\end{array}$ & 11 & 1,6 & - & - & - & - & - & - & 12 & 0,5 & 23 \\
\hline & $\begin{array}{l}\text { Chenopodium L. / } \\
\text { Amaranthus L. }\end{array}$ & Indeterminado & $\begin{array}{l}\text { Grano (fruto } \\
\text { /semilla) }\end{array}$ & 38 & 5,5 & - & - & 3 & 0,7 & 31 & 3,4 & 82 & 3,5 & 124 \\
\hline Cactaceae & Trichocereus L. & Maleza ruderal & Semilla & 12 & 1,8 & - & - & - & - & 1 & 0,1 & 31 & 1,3 & 44 \\
\hline Cucurbitaceae & Cucurbita L. & Indeterminado & Semilla & - & - & - & - & - & - & 3 & 0,3 & - & - & 3 \\
\hline \multirow[t]{2}{*}{ Fabaceae } & $\begin{array}{l}\text { Geoffroea decorticans } \\
\text { (Gillies ex Hook. et Arn.) } \\
\text { Burkart. }\end{array}$ & Silvestre & Endocarpo & 2 & 0,3 & - & - & - & - & - & - & 2 & 0,1 & 4 \\
\hline & $\begin{array}{l}\text { Prosopis aff. alba Griseb. / } \\
\text { nigra (Griseb.) Hieron. / } \\
\text { flexuosa DC. / chilensis } \\
\text { (Molina) Stuntz emend. } \\
\text { Burkart }\end{array}$ & Silvestre & Semilla & 1 & 0,1 & - & - & - & - & - & - & 1 & 0,0 & 2 \\
\hline \multirow[t]{2}{*}{ Malvaceae } & $\begin{array}{l}\text { Cristaria dissecta } \\
\text { Hook. et Arn. }\end{array}$ & $\begin{array}{l}\text { Maleza } \\
\text { agrícola }\end{array}$ & Semilla & - & - & - & - & - & - & - & - & 21 & 0,9 & 21 \\
\hline & Indeterminado & $\begin{array}{c}\text { No } \\
\text { domesticada }\end{array}$ & Semilla & 3 & 0,4 & 1 & 0,3 & - & - & - & - & - & - & 4 \\
\hline Poaceae & Zea mays L. & Domesticada & Fruto & 4 & 0,6 & - & - & - & - & - & - & 2 & 0,1 & 6 \\
\hline Solanaceae & $\begin{array}{l}\text { Solanum aff. } \\
\text { elaeagnifolium Cav. }\end{array}$ & $\begin{array}{l}\text { Maleza } \\
\text { ruderal }\end{array}$ & Semilla & - & - & - & - & - & - & - & - & 1 & 0,0 & 1 \\
\hline \multirow[t]{6}{*}{ Indeterminado } & - & - & - & 9 & 1,3 & - & - & 1 & 0,2 & 14 & 1,5 & 35 & 1,5 & 59 \\
\hline & Total & & & 82 & & 1 & & 4 & & 328 & & 190 & & 605 \\
\hline & Densidad (litro) & & & 12 & & 0,3 & & 0,9 & & 36,2 & & 8,1 & & 12,7 \\
\hline & Cantidad de taxa & & & 8 & & 1 & & 1 & & 4 & & 9 & & 10 \\
\hline & Sedimento flotado (litro) & & & - & & - & & - & & - & & 23 & & 23 \\
\hline & Sedimento tamizado (litro) & & & 6,85 & & 3,75 & & 4,45 & & 9,05 & & 0,5 & & 24,6 \\
\hline
\end{tabular}

\section{RESULTADOS}

\section{Macrorrestos vegetales}

A partir de los 47,6 litros de sedimento analizados se recuperaron un total de 605 carporrestos en estado carbonizado, que en su conjunto representan una densidad de 12,7 carporrestos por litro de sedimento. Se identificó el $90 \%$ de los carporrestos recuperados, los cuales corresponden a siete familias: Amaranthaceae, Cactaceae, Cucurbitaceae, Fabaceae, Malvaceae, Poaceae y Solanaceae (Tabla 2). En cuatro de ellas (Amaranthaceae, Cactaceae, Fabaceae y Poaceae) se identificaron 73 restos con diversos rasgos de procesamiento (Tabla 3).
Amaranthaceae. Granos enteros y fragmentados de forma lenticular aplanada con embrión curvo, tegumentos y embriones sueltos. Se distinguen tres grupos. Chenopodium quinoa "quinoa/ajara". Granos de 1-1,6 mm de diámetro (promedio 1,2 $\mathrm{mm}$ ), con márgenes redondeados a truncados y embrión no solapado. Si bien el margen truncado es un rasgo característico de la variedad domesticada (Bruno \& Whitehead, 2003), para poder confirmarlo se requiere de una mayor cantidad de caracteres y de su combinación con el espesor y textura de la testa, el rasgo que, particularmente, ha sido modificado durante el proceso de domesticación (López et al., 2015). Por lo tanto, no es posible discernir aún si corresponden a C. quinoa var. quinoa (domesticada) 
Tabla 3. Macrorrestos con marcas de procesamiento recuperados en los sitios Morro del Fraile (MF), El Carmen 1 (EC1) y El Carmen 2 (EC2). S, sector; R, recinto.

\begin{tabular}{|c|c|c|c|c|c|c|c|c|c|}
\hline & Taxón & $\begin{array}{l}\text { Marca de } \\
\text { procesamiento }\end{array}$ & $\begin{array}{c}\text { MF } \\
\text { SIII } \\
\text { Alero }\end{array}$ & & $\begin{array}{l}\text { EC1 } \\
\text { SVI } \\
\text { R13 }\end{array}$ & & $\begin{array}{c}\mathrm{EC} 2 \\
- \\
\mathrm{R} 2\end{array}$ & & Total \\
\hline & & & $\mathrm{n}$ & muestra & $\mathrm{n}$ & muestra & $\mathrm{n}$ & muestra & $\mathrm{n}$ \\
\hline \multirow[t]{3}{*}{ Amaranthaceae } & Chenopodium quinoa Willd. & $\begin{array}{l}\text { Granos sin } \\
\text { embrión }\end{array}$ & 1 & V10 & 10 & $\begin{array}{l}\text { V06, V11, } \\
\text { V12, V13, } \\
\text { V15 }\end{array}$ & - & - & 11 \\
\hline & \multirow[t]{2}{*}{$\begin{array}{l}\text { Chenopodium L./ } \\
\text { Amaranthus L. }\end{array}$} & $\begin{array}{l}\text { Granos sin } \\
\text { embrión }\end{array}$ & 3 & $\begin{array}{l}\text { V12, } \\
\text { V14 }\end{array}$ & - & - & 1 & V13 & 4 \\
\hline & & $\begin{array}{l}\text { Embriones } \\
\text { sueltos }\end{array}$ & - & - & 30 & $\begin{array}{l}\text { V06, V11, } \\
\text { V13, V15 }\end{array}$ & 17 & $\begin{array}{l}\text { V04, V16, V19, } \\
\text { V22, V23, V28, } \\
\text { V29, V30, V32 }\end{array}$ & 47 \\
\hline Cactaceae & Trichocereus L. & $\begin{array}{l}\text { Semillas sin } \\
\text { opérculo }\end{array}$ & 1 & V26 & - & - & 7 & $\begin{array}{l}\text { V06, V10, V19, } \\
\text { V20, V23, V26 }\end{array}$ & 8 \\
\hline Fabaceae & $\begin{array}{l}\text { Prosopis aff. alba Griseb. / } \\
\text { nigra (Griseb.) Hieron. / } \\
\text { flexuosa DC. / chilensis } \\
\text { (Molina) Stuntz emend. Burkart }\end{array}$ & $\begin{array}{l}\text { Semillas con } \\
\text { testa fisurada } \\
\text { y/o plegada }\end{array}$ & 1 & V14 & - & - & 1 & V22 & 2 \\
\hline \multirow[t]{2}{*}{ Poaceae } & Zea mays $\mathrm{L}$. & $\begin{array}{l}\text { Fruto con } \\
\text { células aleurona } \\
\text { visibles }\end{array}$ & - & - & - & - & 1 & V08 & 1 \\
\hline & Total & & 6 & & 40 & & 27 & & 73 \\
\hline
\end{tabular}

o a C. quinoa var. melanospermum (maleza agrícola). Se identificaron 11 restos con rasgos de procesamiento por hervido: granos sin embrión (Tabla 3, Fig. 2A-B). Chenopodium. Tegumentos sueltos de 0,9-1,1 mm de diámetro (promedio $1,0 \mathrm{~mm}$ ), con márgenes biconvexos a ecuatoriales, embrión en forma envolvente y textura de la superficie del tegumento reticulada (Fig. 2C), podrían corresponder a especies silvestres, malezas o domesticadas. Cabe destacar que márgenes biconvexos o ecuatoriales y textura reticular de la testa son rasgos que caracterizan a Chenopodium quinoa var. melanospermum (Bruno \& Whitehead, 2003). Chenopodium / Amaranthus "amaranto". No se pudo determinar si lo granos de un tamaño muy pequeño $(0,5-1,4 \mathrm{~mm}$ de diámetro; promedio $0,8 \mathrm{~mm}$ ) pertenecen al género Amaranthus o Chenopodium (Fig. 2D); estos podrían corresponder a especies silvestres, malezas o domesticadas. Se identificaron 51 restos con rasgos de procesamiento por hervido: cuatro granos sin embrión y 47 embriones sueltos (Tabla 3, Fig. 2E).

Cactaceae. Trichocereus "cardón". Semillas pequeñas de 1-1,4 x 0,8-1,0 mm, en forma de coma aplastada lateramente o de ánfora, hilo terminal con un oficio micropilar y otro funicular y testa con aspecto punteado. Se identificaron ocho restos con rasgos de procesamiento: semillassin opérculo(Tabla3, Fig.2F).
De acuerdo con Petrucci (2017), la ausencia del opérculo se debe a la germinación de las semillas producto de algún tipo de procesamiento de los frutos previo a la carbonización, tales como la fermentación para la elaboración de bebidas alcohólicas. Corresponden a un género de cardón columnar que puede comportarse como maleza ruderal debido a su adaptación a ambientes disturbados (Petrucci, 2017).

Cucurbitaceae. Cucurbita "zapallo". Semilla elíptica, cerca de 12,3 × 6 mm, aplanada, superficie lisa, con reborde marginal (rafe) más o menos pronunciado (Fig. 2G); podría corresponder a una especie silvestre o domesticada.

Fabaceae. Geoffroea decorticans "chañar". Fragmentos del endocarpo con estrías transversales en la superficie interna (Fig. 2H); especie silvestre. Prosopis aff. alba / nigra / flexuosa / chilensis "algarrobo". Semillas de forma aovada a aovadaelíptica ligeramente aplanadas, de 4-5,2 x 2,6-3,8 $\mathrm{mm}$, ápice redondeado, embrión curvo o recto, línea fisural en forma circular o de herradura; especies silvestres. Se identificaron dos restos con rasgos de procesamiento: semillas con fisuras en la testa y una de ellas, además, con pliegues, que indican que han sufrido algún procesamiento previo a la carbonización (Capparelli, 2008) (Tabla 3, Fig. 2I). 

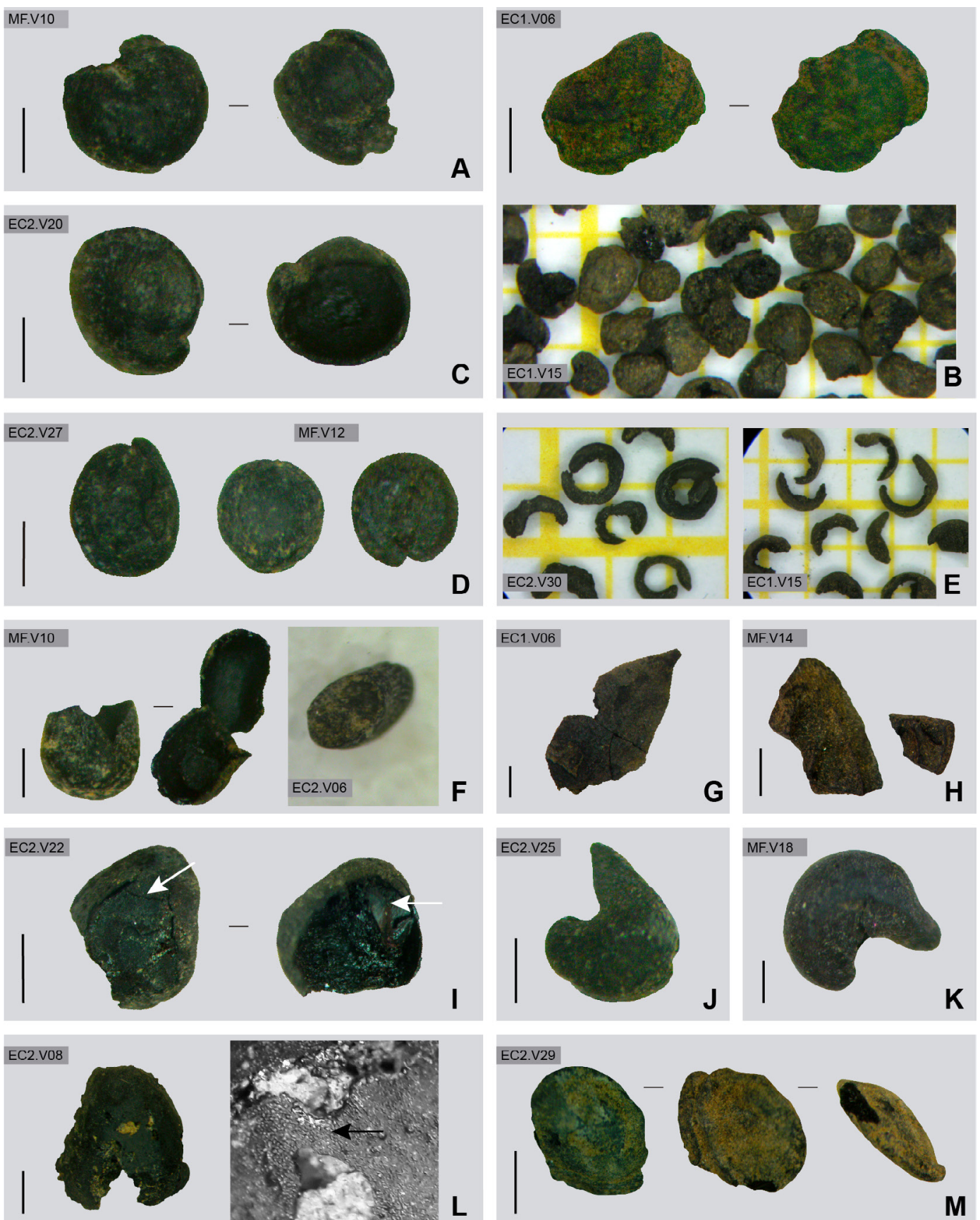

Fig. 2. Macrorrestos identificados en los sitios arqueológicos Morro del Fraile (MF), El Carmen 1 (EC1) y El Carmen 2 (EC2). A, grano de Chenopodium quinoa sin embrión. B, granos de C. quinoa y detalle de grano sin embrión. C, tegumento de Chenopodium con margen biconvexo a ecuatorial y superficie reticulada. D, granos de Chenopodium/Amaranthus. E, embriones de Chenopodium/Amaranthus. F, semillas de Trichocereus, entera y transcorte mostrando su carbonización, semilla sin opérculo. G, semilla de Cucurbita. H, endocarpos de Geoffroea decorticans con estrías transversales internas. I, semilla de Prosopis con la testa fisurada y plegada. J, semilla de Cristaria dissecta con extremo radicular aguzado. K, semilla de Malvaceae con extremo radicular redondeado. L, fruto de Zea mays, detalle de células de la capa de aleurona. M, semilla de Solanum aff. elaeagnifolium en diferentes vistas. Escalas: A-D, F, J-K: 0,5 mm; G-I, L-M: 2 mm. Figura en color en la versión en línea http://www.ojs.darwin.edu.ar/index.php/darwiniana/article/view/939/1211 
Malvaceae. Cristaria dissecta. Semillas de morfología arriñonada, de 1-1,4 x 0,8-1 mm, con extremo radicular aguzado (Fig. 2J). Estas semillas han sido recuperadas en sitios arqueológicos de Chile (García \& Uribe, 2012, fig. 6); en la Argentina se conocen dos especies del género Cristaria, $C$. andicola Gay y $C$. dissecta (Muñoz-Schick, 1995). Cristaria dissecta se diferencia de C. andicola por presentar semillas de un tamaño menor (2-2,5 x 1-1,5 $\mathrm{mm}$ en $C$. andicola); especie no domesticada que crece entre los campos de cultivo, comportándose como maleza agrícola (Villagrán et al., 1998). Malvaceae indet. Semillas de morfología arriñonada, de 1,8-2,1 x 1,5-1,7 mm, con extremo radicular redondeado (Fig. 2K); confrontar con Sida rhombifolia L., Pavonia glechomoides A. St.-Hil., P. aurigloba Krapov. \& Cristóbal, Sphaeralcea bonariensis (Cav.) Griseb., especies registradas en el área de estudio (Petrucci, 2017); corresponden a especies no domesticadas pudiendo representar formas silvestres o, tal y como ha sido registrado en los campos de cultivo actuales del NOA, malezas agrícolas (Lema, 2014).

Poaceae (Gramíneas). Zea mays "maíz". Fruto (grano) obovado, cuneiforme, superficie externa lisa de aspecto lustroso, estructura interna porosa, embrión lateral y basal, de 5,2-7 x 3,3-6,4 mm; especie domesticada. En uno de los granos recuperados, se observaron las células de la capa de aleurona que indican la apertura del pericarpio como consecuencia del hervido de los granos (Petrucci \& Lema, 2016) (Tabla 3, Fig. 2L).

Solanaceae. Solanum aff. elaeagnifolium. Semilla lenticular, embrión curvo, superficie lisa, ca. 4,5 x $3,4 \mathrm{~mm}$ (Fig. 2M); especie que crece en ambientes disturbados por los seres humanos, comportándose como maleza ruderal (Zuloaga et al., 2019).

La mayor cantidad de restos vegetales fue recuperada en pisos de ocupación con fogones más o menos definidos y con un buen grado de remontaje y asociación de fragmentos cerámicos, como MF.A y EC1.R13. La ausencia de carporrestos en el fogón asociado a cerámica con buen grado de remontaje de EC1.R1, en relación a la gran densidad de restos recuperados en otros fogones del mismo sitio, podría acompañar la hipótesis de un uso diferente del sector I, tal y como fue postulado por Cantarelli (2019).
En los contextos donde la cerámica presenta un menor grado de asociación y remontaje, en algunos casos, como EC2.R2, se recuperaron restos mientras que, en otros, como MF.R1, no se recuperaron carporrestos. Teniendo en cuenta la cercanía de este último al mortero múltiple, en donde podrían haberse procesado diversos alimentos, la ausencia de carporrestos registrada podría deberse a la escasa cantidad de litros analizados. En el piso de ocupación de MF.R1 sólo se ha recuperado una semilla de Malvaceae y en el sedimento proveniente del fogón del piso de ocupación de EC1.R1 sólo cuatro restos.

A fin de realizar el análisis diacrónico propuesto, se compararon los tres contextos donde se concentran la casi totalidad de los 605 carporrestos encontrados (Tabla 2): MF.A (766-1380 d.C.), EC1. R13 (1222-1405 d.C.) y EC2.R2 (436-602 d.C. / 1463-1627 d.C.). Teniendo en cuenta la densidad de restos recuperados, EC1.R13 es el que presenta una mayor densidad con 36 carporrestos/litro; le siguen MF.A y EC2.R2, con 8-12 carporrestos/litro. Sólo nueve muestras presentan densidades mayores a un carporresto/litro (Fig. 3A-B). En EC1.R13 y MF.A coincide con que estas muestras concentran la mayoría de los restos recuperados, el $98 \%$ y $72 \%$ respectivamente. En EC2.R2, sin embargo, la mayoría de los restos (el 63\%) se encuentra de manera más o menos homogénea a lo largo de 22 muestras provenientes del piso de ocupación, con densidades menores a 0,5 carporrestos/litro. Las únicas excepciones son las muestras EC2. V30 y EC2.V34 que fueron recuperadas junto a una delimitación de piedras con una de ellas en posición casi vertical (rasgo 15) que, en función de la concentración de carporrestos asociados, fue interpretada como fogón. Así, la proporción de restos recuperados en estructuras de combustión en EC2.R2 es de $37 \%$, de modo similar a MF.A, donde la proporción es del 54\%; en EC1.R13, casi la totalidad de los restos recuperados (el 98\%) proviene del fogón identificado (Fig. 3A-B).

MF.A y EC2.R2 son los que presentan una mayor diversidad de plantas (Fig. 4A), con la particularidad de presentar casi la misma asociación y en las mismas proporciones, con un predominio de Amaranthaceae, seguido de Trichocereus y Malvaceae, y en bajas proporciones Geoffroea decorticans, Prosopis y Zea mays, estando ausente el género Cucurbita que encontramos únicamente en EC1.R13. 


\section{Morro del Fraile}

Alero - Cuadrícula 1

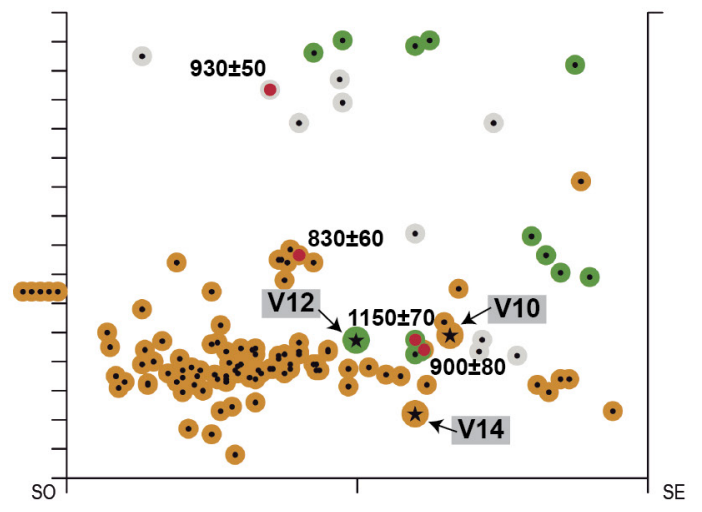

El Carmen 1

Recinto 13 - Cuadrícula 1 y 2

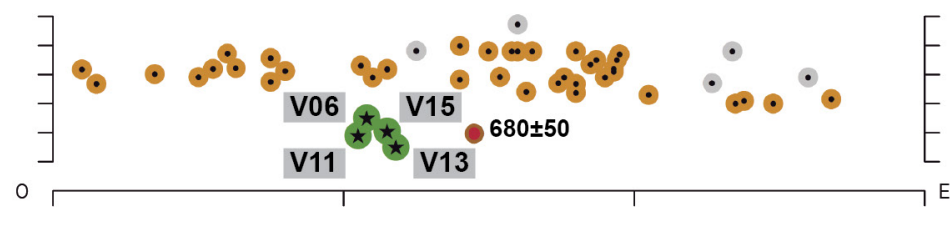

\section{El Carmen 2}

Recinto 2 - Cuadrícula 1

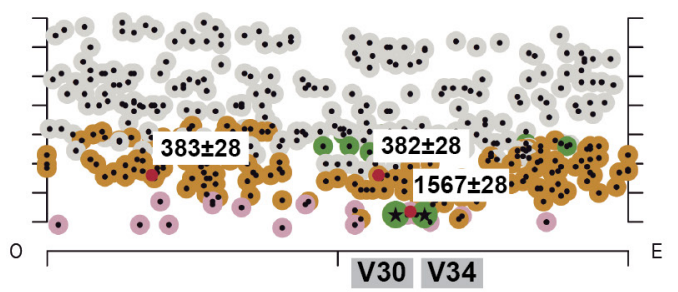

\footnotetext{
sedimento ceniza/fogón

piso de ocupación

relleno

- fechados radiocarbónicos

$\star$ sedimento analizado

- materiales
}

0

$100 \mathrm{~cm}$
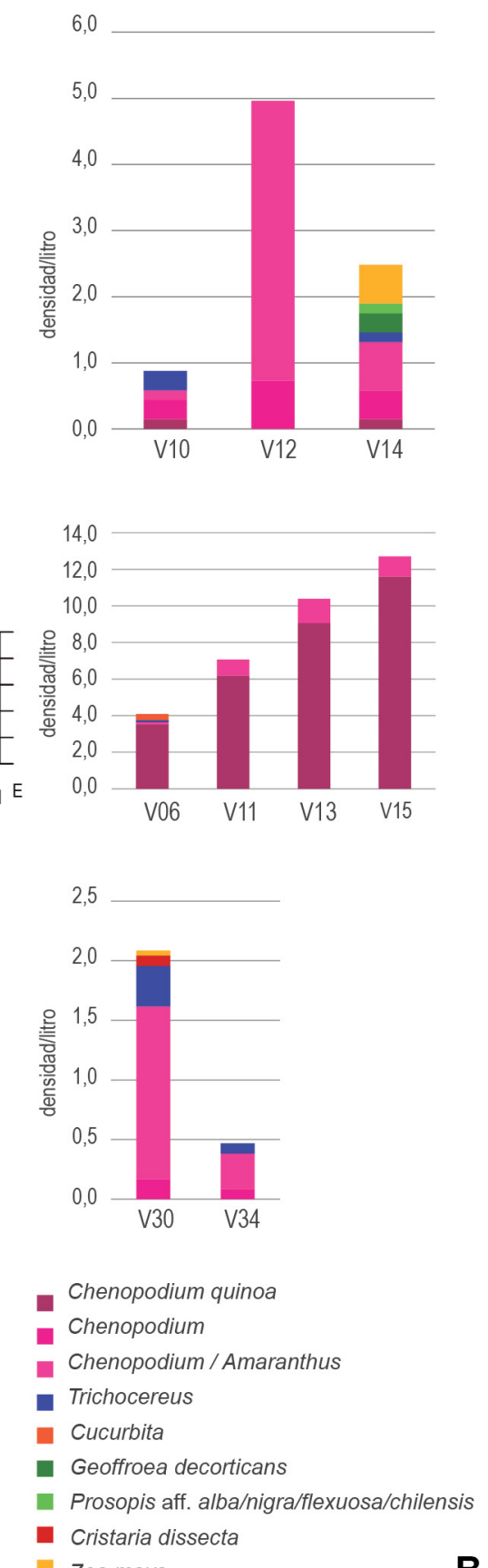

A $\square$ Zea mays

B

Fig. 3. Procedencia y composición de las nueve muestras con densidad mayor o igual a 1 carporresto/litro de los sitios Morro del Fraile, El Carmen 1 y El Carmen 2. A, asociación con fechados radiocarbónicos y ubicación en los pisos de ocupación y/o fogones. B, composición de las muestras por taxón, de acuerdo a la densidad de carporrestos por litro de sedimento. Figura en color en la versión en línea http://www.ojs.darwin.edu.ar/index. php/darwiniana/article/view/939/1211 


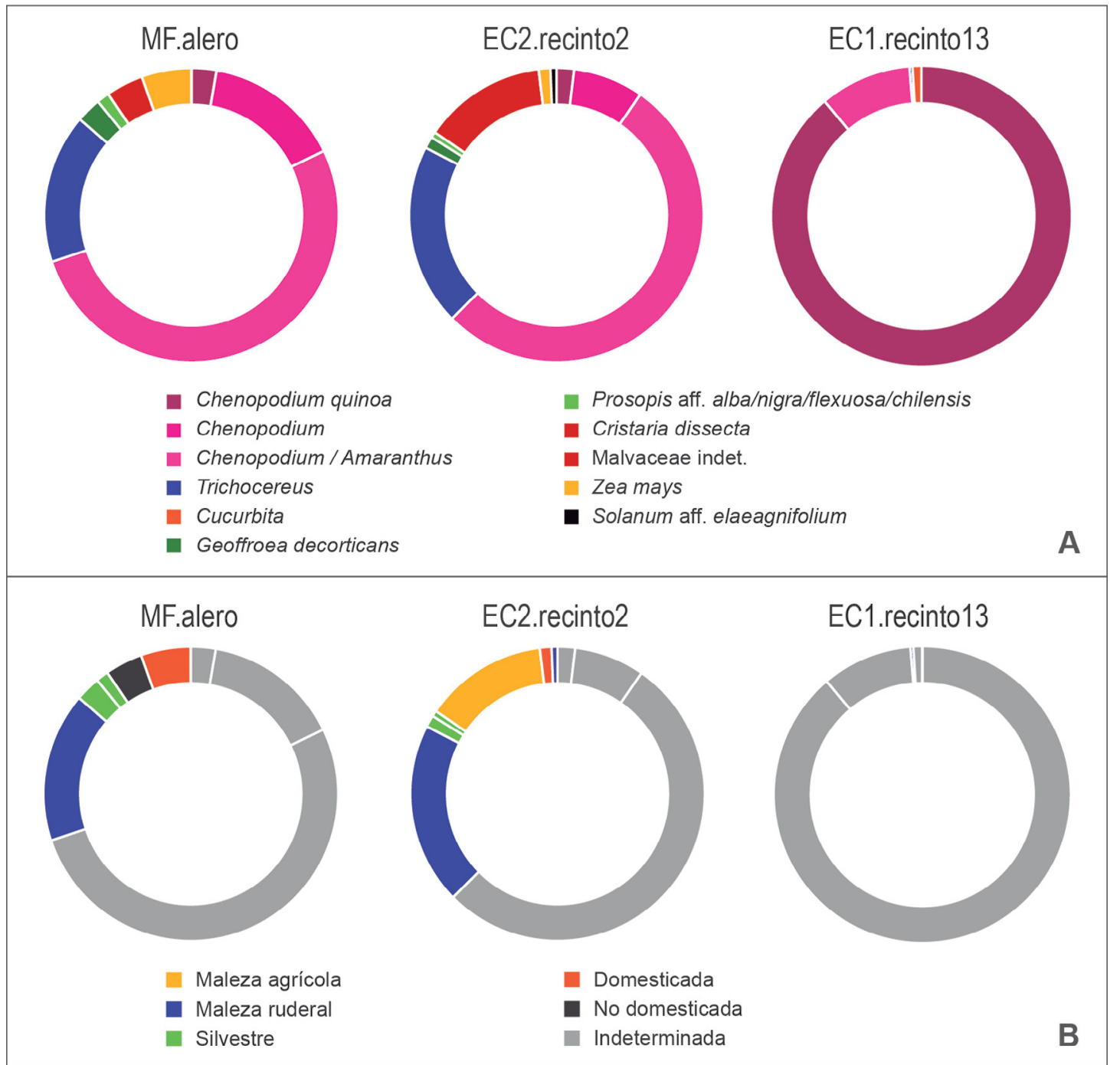

Fig. 4. Proporción de macrorrestos recuperados en los sitios Morro del Fraile (MF), El Carmen 1 (EC1) y El Carmen 2 (EC2). A, según su composición taxonómica. B, según el grado de asociación humano-planta. Figura en color en la versión en línea http://www.ojs.darwin.edu.ar/index.php/darwiniana/article/view/939/1211

El taxón con mayor densidad de restos recuperados en todos los sitios es Amaranthaceae, con 4,1 carporrestos/litro en EC2.R2, 7,4 carporrestos/litro en MF.A y 34,2 carporrestos/litro en EC1.R13. El segundo taxón con mayor densidad es el género Trichocereus con densidades similares en MF.A y EC2.R2 y, en tercer lugar, Cristaria dissecta en EC2.R2. El resto de los taxones se encuentran en bajas densidades, menores a 0,6 carporrestos/ litro. Si bien la familia Amaranthaceae es el taxón predominante en todos los sitios, se presenta bajo dos patrones diferentes que corresponden a la mayor y menor homogeneidad de los restos encontrados. MF.A y EC2.R2 comparten una asociación similar de diversos granos que podrían corresponder a la variedad domesticada y/o maleza de la especie Chenopodium quinoa, así como a especies silvestres, malezas y/o domesticadas de los géneros Amaranthus y Chenopodium. En EC1. R13 los restos encontrados son muy homogéneos entre sí correspondiendo casi en su totalidad a la especie C. quinoa. 
La diversidad de plantas identificadas en MF.A y EC2.R2 se corresponde con distintos grados de asociación humano-planta (Fig. 4B). En estos dos contextos encontramos malezas, como el cardón, plantas silvestres, como el chañar y el algarrobo, así como plantas domesticadas, como el maíz. En estos casos, también, la presencia conjunta de diversos granos de Amaranthaceae podría incluir especies silvestres, malezas y/o domesticadas; mientras que en EC1.R13 las especies de la familia Amaranthaceae corresponderían, principalmente, a la variedad maleza y/o domesticada de Chenopodium quinoa.

\section{Microrrestos vegetales}

En los sitios EC1.R1 y EC2.R2, se recuperaron un total de 10 microrrestos diagnósticos provenientes del raspado de fragmentos cerámicos que se corresponden con Zea mays y Cucurbita sp.

Fitolitos de Zea mays. Presentan forma de cono truncado, morfotipo característico de la mazorca del maíz (Bozarth, 1993; Piperno \& Pearsall, 1993). El que se observa en la Figura $5 \mathrm{~A}$, presenta la base plana y circular, algo más larga que el cuerpo $(12 \times 8 \mu \mathrm{m})$ y la parte superior es ondulada. Las características del ápice (longitud igual o menor a la de la base y forma ondulada) lo acercarían a la especie Zea mays. De tamaño apenas mayor $(16 \times 10 \mu \mathrm{m}) \mathrm{y}$ de forma más alargada, el fitolito de la Figura $5 \mathrm{~B}$, también presenta las características del cono trucado de maíz: base ovalada más larga que el cuerpo y ondulaciones en la parte superior. Estos fitolitos fueron hallados por raspado de la superficie interna en las ollas peinadas con baño EC1.G01 (Figs. 5A y 5B) y EC1. G02 (Fig. 5C), en la vasija EC2.G03 pulida de forma indeterminada (Figs. 5E y 5F) y en la olla Caspinchango EC2.G05 (Fig. 5I). En el fitolito del Puco Yutopián/Soria EC2.M04, la base es más larga que el cuerpo, aunque no puede llegar a determinarse su forma ya que podría ser bilobada, modificando así la morfología, o podría ser que se encuentre muy alterado, por razones de procesamiento o tafonómicos; se encuentra fragmentado midiendo $5 \mu \mathrm{m}$ el cuerpo y al menos $10 \mu \mathrm{m}$ la base (Fig. 5D).
Fitolitos afines a Cucurbita sp. Con menor grado de probabilidad se identificaron otros fitolitos que podrían corresponderse con las esferas facetadas características de la cáscara del fruto de Cucurbita sp. (Bozarth, 1987). Estos fitolitos presentan algunas facetas en su superficie y su tamaño es menor a los característicos de este género (Figs. 5G-H y 5J). Estos fitolitos fueron hallados en la vasija EC2.G03 y en la olla Caspinchango EC2.G05.

En ninguna de las muestras analizadas se recuperaron almidones. Al observar la primera muestra del raspado de las cerámicas (f1255, EC2.G04) se identificaron estructuras que bajo luz polarizada brillan y presentan líneas que se asemejan a las cruces de los granos de almidón. Sin embargo, sólo son visibles bajo luz polarizada (vs. los granos de almidón visibles con luz normal) y la cruz, si bien gira, presenta brazos sin un patrón definido, los márgenes son difusos y no se tiñen de color negro con lugol. Se pudieron reconocer diferentes estructuras (Fig. $5 \mathrm{~K})$ que se pueden confundir con almidones y que se identificaron como muscovita a partir de una muestra de referencia tomada de un fragmento cerámico.

\section{DISCUSIÓN}

\section{Vías de ingreso de los macrorrestos carbonizados}

De acuerdo con Pearsall (2016), los restos de plantas ingresan a los fogones de los espacios domésticos ya sea como combustible, como alimentos que requieren del uso del fuego para su preparación o de manera accidental en el marco de las actividades diarias. Si bien estudios realizados en estiércol de camélidos en Bolivia y Perú muestran que el estiércol de camélido utilizado como combustible contiene regularmente semillas (Hastorf \& Wright, 1998), en los contextos analizados no se han recuperado restos de guano quemado que pudieran alertarnos acerca de esta última posibilidad. Por el contrario, la presencia de marcas de procesamiento en macrorrestos de Amaranthaceae en el fogón de EC1.R13 (granos sin embrión y embriones sueltos), 

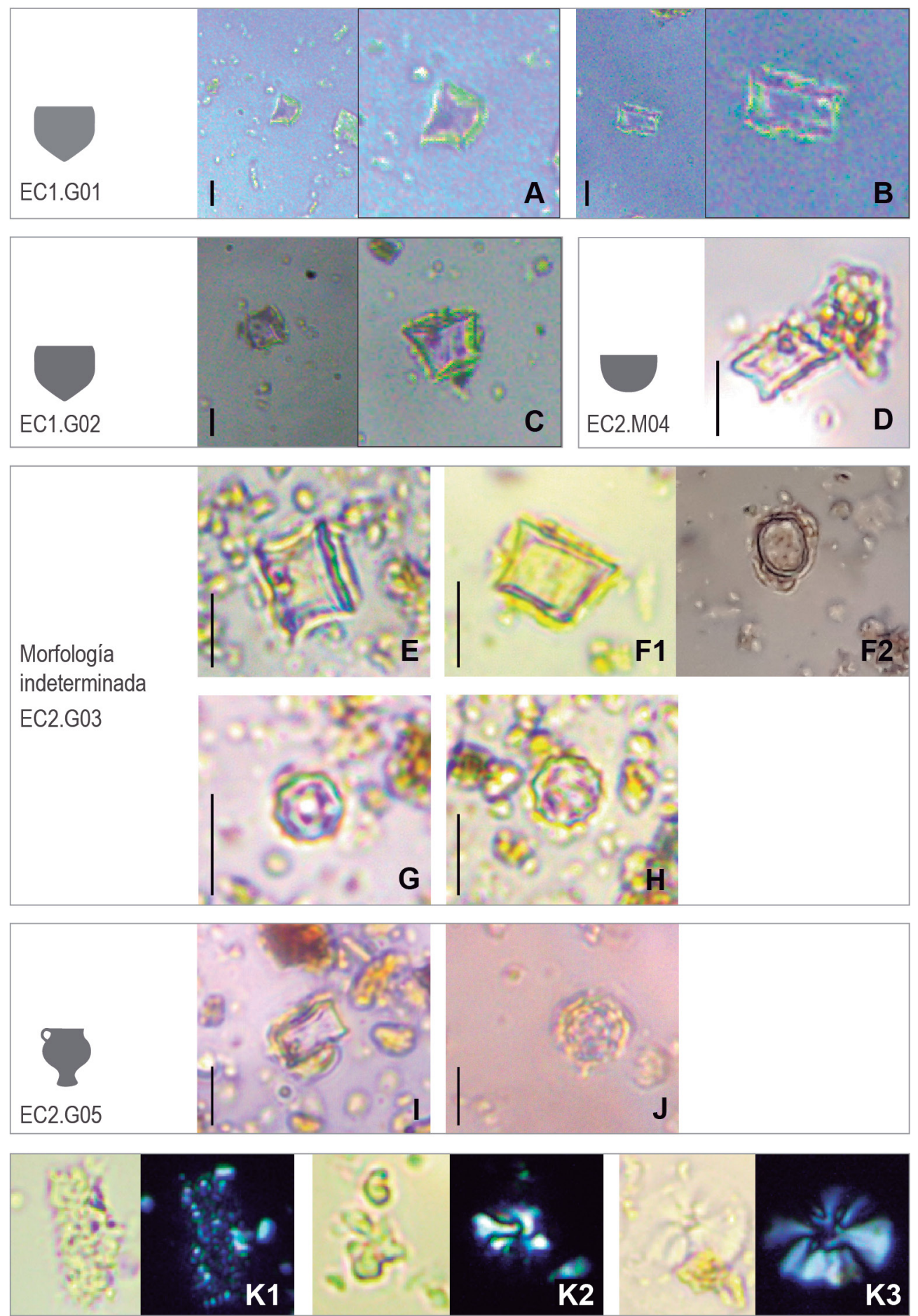

Fig. 5. Microrrestos recuperados en vasijas de los sitios arqueológicos El Carmen 1 (EC1) y El Carmen 2 (EC2). A, I, fitolito cono truncado de Zea mays. B-F, fitolito cono truncado aff. Zea mays. B-F1, vista de perfil. F2, vista de la base. $\mathbf{G - H}$, fitolito esfera facetada aff. Cucurbita. J, fitolito esfera facetada Cucurbita. K, estructuras similares a almidones con luz normal y polarizada. K1-2, en mica de referencia. K3, en material proveniente del raspado de la cerámica. Escalas: $10 \mu \mathrm{m}$. Figura en color en la versión en línea http://www.ojs.darwin.edu.ar/index.php/darwiniana/article/view/939/1211 
en el fogón y piso de MF.A (granos sin embrión) y en el fogón y piso de EC2.R2 (granos sin embrión y embriones sueltos) (Tabla 3, Fig. 2A-B, E), producto de su cocción mediante hervido (López et al., 2012), indican el ingreso de estos granos como alimento. Del mismo modo, la presencia de granos de maíz en los que se observan las células de la capa de aleurona (Tabla 3, Fig. 2L), producto de la apertura del pericarpio por el hervor de los granos (Petrucci \& Lema, 2016), evidencian también que hubo actividades vinculadas con la cocción de alimentos. Por otra parte, la presencia de semillas carbonizadas de frutos cuyos procesamientos ligados al fuego son escasos y que presentan marcas de algún tipo de procesamiento podría explicarse a partir de actividades no vinculadas estrictamente a los fogones habiendo ingresado a ellos de manera accidental. Así, el hallazgo de Prosopis sp. en los pisos de ocupación de MF.A y EC2.R2 con testa fisurada y/o plegada (Tabla 3; Fig. 2I) indica que diversos procesamientos habrían afectado a las semillas encontradas (Capparelli, 2008). Lo mismo ocurre con la identificación de semillas sin opérculo de Trichocereus sp. (Tabla 3; Fig. 2F), que indican el aprovechamiento de sus frutos para la elaboración de bebidas fermentadas, tal y como fue recientemente postulado para tiempos prehispánicos en los sitios Soria 2 y Rincón Chico (Petrucci, 2017). Finalmente, la presencia de semillas sin rasgos de procesamiento de Cristaria dissecta, Malvaceae y Solanum aff. elaeagnifolium podría explicarse a partir del ingreso accidental como malezas con los cultivos. Particularmente, las semillas de Cristaria dissecta, distribuidas a lo largo de toda la excavación de EC2.R2, podrían estar relacionadas con el almacenaje debido a que se las ha identificado vinculadas a actividades pastoriles, como forraje para animales en sitios de Chile (García \& Uribe, 2012). Cristaria dissecta es una especie muy común en las regiones áridas de Chile, y, de acuerdo con Zuloaga et al. (2019), en la Argentina ha sido recolectada en las provincias de Salta, San Juan, Mendoza y Neuquén. Su presencia en la zona de estudio podría ser otra de las evidencias de los diversos objetos, materias primas y, quizás, plantas que fueron traídos de la puna (ya sea de Salta o Chile) como parte de las caravanas realizadas por los pastores andinos.

\section{Prácticas de consumo y manejo de plantas}

En función de la semejanza de las evidencias provenientes, principalmente, de macrorrestos, las posibles prácticas se analizaron en MF.A-EC2. R2 y en EC1.R1-R13.

MF.A y EC2.R2. La presencia de restos carbonizados de semillas de Prosopis sp., Trichocereus sp., endocarpos de Geoffroea decorticans, granos de diversas Amaranthaceae (Chenopodium quinoa, Chenopodium y/o Amaranthus) y de Zea mays, en su mayoría con marcas de procesamiento, en pisos de ocupación con fogones y vasijas cerámicas con hollín, nos permite pensar que fueron parte de los alimentos consumidos en los espacios residenciales de los sitios MF y EC2 (Fig. 6B-C). Del mismo modo, la presencia de microrrestos en las vasijas cerámicas de EC2.R2 indican que allí se elaboraron y/o consumieron alimentos y que Zea mays y, quizás, Cucurbita habrían sido parte de ellos (Fig. 6C). Para el algarrobo, se propone su cultivo en el salar de Atacama (Chile) donde las especies de este género no son nativas (McRostie, 2014). En el valle de Santa María, si bien es probable que hayan sido cultivados dada la relevancia social que representan, aún no se realizaron análisis que permitan confirmar o refutar dicha posibilidad, por lo que, al igual que Geoffroea decorticans, se los consideró como producto de la recolección (Petrucci \& Tarragó, 2015; Petrucci \& Spano, 2019). De acuerdo con Petrucci et al. (2018), los miembros del grupo Trichocereus pueden comportarse como "malezas" debido a su gran abundancia en hábitats disturbados por las actividades humanas y su estrecha asociación con sitios arqueológicos. En este sentido, la presencia de restos de Trichocereus sp. con densidades de 1,3 y 1,8 carporrestos/litro, siendo el segundo taxón con mayor densidad de restos recuperados, podría indicar que la tolerancia y el fomento entre otras formas de manejo (Casas, 2001), además de la recolección, podrían haber sido parte de las diversas prácticas de interacción, aún poco conocidas, entre los seres humanos y los cardones en el pasado prehispánico del noroeste argentino. Con respecto al maíz, los estudios de Coll Moritan \& Nastri (2015) indican que los suelos de MF no habrían permitido su cultivo, habiéndose obtenido probablemente por medio del intercambio o traslado hacia el fondo del valle del río Santa María. 

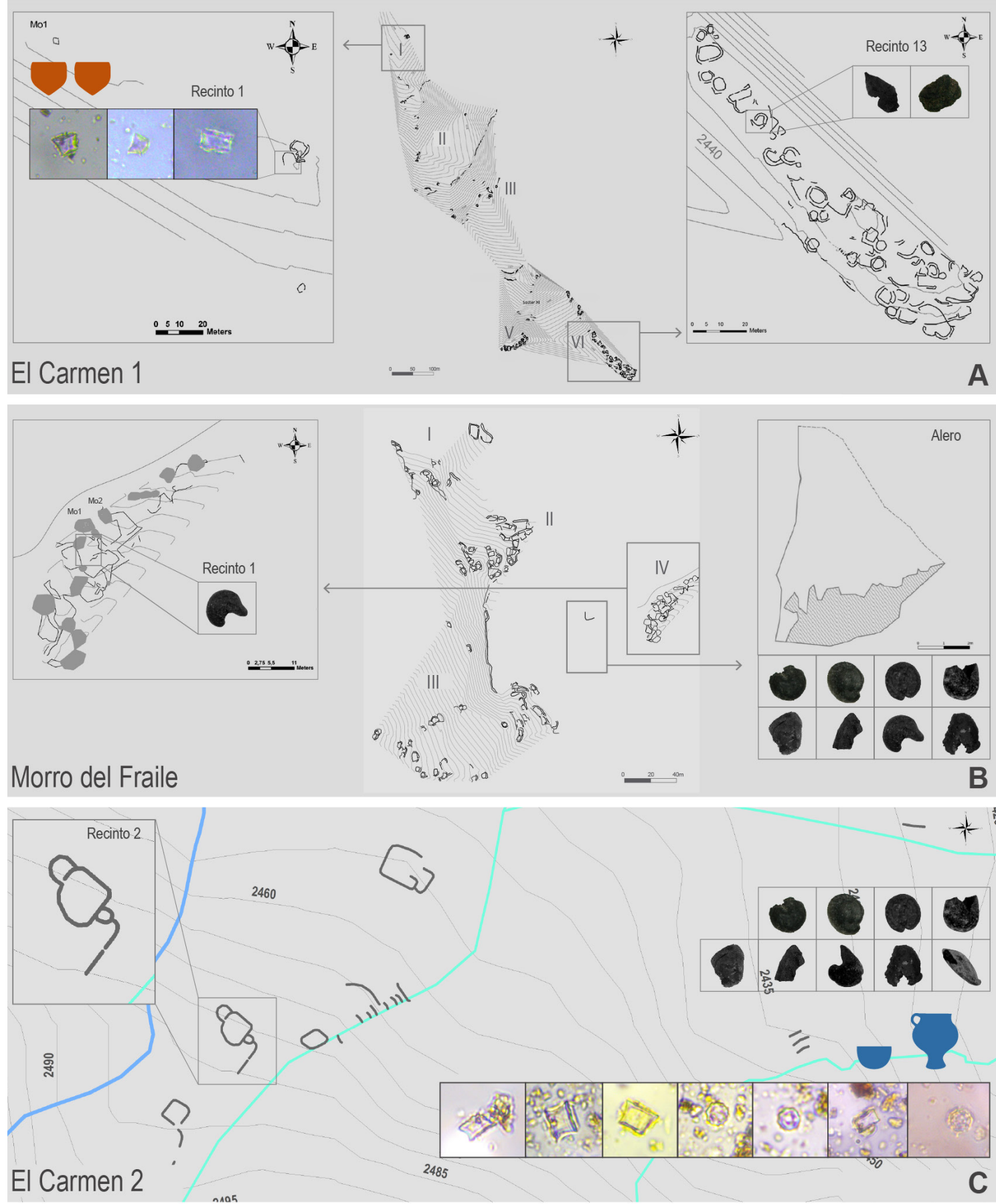

Fig. 6. Distribución espacial de macro y microrrestos. A, El Carmen 1 (modificado de Coll Moritan et al., 2015). Centro, plano general del sitio; izquierda, sector I y restos recuperados en el recinto 1; derecha, sector VI y restos recuperados en el recinto 13. B, Morro del Fraile (modificado de Coll Moritan, 2018b). Centro, plano del sitio; izquierda, sector IV y restos recuperados en el recinto 1; derecha, restos recuperados en el alero. C, El Carmen 2 (modificado de Longo, 2020), Unidad Arquitectónica 2 y restos recuperados en el recinto 2. Figura en color en la versión en línea http://www.ojs.darwin.edu.ar/index.php/darwiniana/article/view/939/1211 
Por el contrario, en EC2 las características del suelo son aptas para su cultivo, pudiendo haber sido una de las plantas cultivadas en las terrazas agrícolas identificadas (Longo, 2020, fig. 4.28). Chenopodium quinoa, ya sea su variante domesticada o maleza agrícola, es otra de las plantas que podría haber ocupado los espacios de cultivo junto con Zea mays en EC2. Tanto MF como EC2 muestran evidencias de haber sido ocupados a lo largo del tiempo, de manera continua en el primero y con reocupaciones en el segundo. En este sentido, la diversidad de plantas y prácticas de manejo identificadas podría ser producto de actividades contemporáneas o de múltiples actividades disociadas en el tiempo.

EC1.R1-R13. La presencia de restos carbonizados de Cucurbita sp. y de gran cantidad de granos de especies de la familia Amaranthaceae con alto grado de semejanza entre sí y evidencias de procesamiento por hervido (embriones sueltos y granos sin embrión) en el fogón de EC1.R13, permite pensar que fueron parte de los alimentos consumidos en los espacios residenciales del sitio EC1. Del mismo modo, la presencia de microrrestos en las vasijas cerámicas de EC1.R1 indicarían que allí se elaboraron alimentos y que Zea mays habría sido parte de ellos (Fig. 6A). En EC1 las Amaranthaceae corresponden a la especie Chenopodium quinoa. Probablemente Zea mays y Chenopodium quinoa, ya sea su variedad domesticada o maleza agrícola, hayan sido algunas de las plantas que habrían ocupado los espacios de cultivo identificados al pie del sitio en el fondo de la quebrada del Carmen (Cantarelli, 2019). Resulta llamativa la ausencia en EC1 de macrorrestos de Zea mays y Prosopis sp., taxones abundantes en los sitios del segundo milenio d.C. como Pichao y Rincón Chico (Cano, 2011; Petrucci \& Tarragó, 2015) y, en su lugar, el alto predominio de Amaranthaceae, que se diferencia, además, por su gran homogeneidad y densidad en comparación con la registrada en sitios contemporáneos (Petrucci \& Tarragó, 2019). La menor diversidad de plantas identificada en EC1.R13 podría deberse a usos diferenciales de los recintos o al bajo volumen analizado. Si bien MF.A con menos litros procesados que EC1.R13 presenta una mayor diversidad de plantas, resulta claro que el bajo volumen muestreado pueda ser una de las razones de la menor diversidad encontrada en EC1.R13. De acuerdo con sus dimensiones, MF.A $\left(20 \mathrm{~m}^{2}\right)$ y EC2.R2 (aprox. $75 \mathrm{~m}^{2}$ ) podrían haber funcionado como espacios en los que se realizarían múltiples actividades. EC1.R13, en cambio, con una superficie mucho menor $\left(10 \mathrm{~m}^{2}\right)$ pudo haber tenido un techado cónico $\mathrm{y}$ haber estado vinculado a actividades específicas (Coll Moritan et al. 2015; Coll Moritan 2018b). En función de los resultados aquí encontrados, EC1.R13 habría funcionado como un espacio de cocción/cocina. De este modo, el muestreo de espacios diferentes también es una causa posible de las diferencias en la mayor o menor diversidad de los vegetales identificados.

\section{Consideraciones temporales}

Teniendo en cuenta los momentos de ocupación de cada sitio, los granos de la familia Amaranthaceae habrían sido las plantas predominantes consumidas a lo largo del tiempo bajo dos patrones diferentes. Desde el primer milenio d.C., se destaca la diversidad de granos de especies de Amaranthaceae que incluye Chenopodium quinoa, Chenopodium y/o Amaranthus, mientras que, desde el segundo milenio d.C., la presencia de Amaranthaceae con mayor homogeneidad de los granos recuperados indica el consumo, casi exclusivo, de Chenopodium quinoa. Los resultados nos permiten inferir, además, que Trichocereus, los frutos de Prosopis sp. y Geoffroea decorticans, así como también de Zea mays, y, con menor grado de probabilidad, de Cucurbita sp., fueron parte de los alimentos consumidos desde el primer milenio d.C. Estos resultados coinciden con la tendencia registrada para el valle de Santa María durante el primer milenio d.C., con una mayor diversidad de plantas y un predominio de Trichocereus sp. (Petrucci et al., 2018), como ocurre en EC2.R2 y MF.A, y difieren de lo conocido para el segundo milenio d.C., donde EC1.R13 muestra una menor diversidad de plantas. MF se asemejaría así a los contextos conocidos del primer milenio d.C. del valle de Santa María y al sitio aquí analizado EC2, y se distancia de EC1 y los sitios del segundo milenio d.C. del citado valle. 


\section{CONCLUSIONES}

El estudio arqueobotánico de los sitios EC1, EC2 y MF, por medio del análisis de macro y microrrestos vegetales de frutos y semillas, permitió obtener un primer acercamiento a la diversidad de plantas que habrían formado parte de los alimentos consumidos y las prácticas de manejo involucradas en su obtención. Los resultados muestran que EC2.R2 y MF.A se asemejan entre sí y se diferencian de manera notoria de EC1.R13.

En MF.A y EC2.R2 se habrían llevado a cabo una gran diversidad de prácticas asociadas al consumo y manejo de plantas, aunque, teniendo en cuenta la densidad en la que aparecen representadas (entre 8,1 y 12,0 carporrestos/ litro), podrían no haber sido tan intensas. La presencia de especies silvestres (Prosopis y Geoffroea decorticans) y malezas (Trichocereus), con rasgos de procesamiento, permite pensar en el consumo de sus frutos y en prácticas de recolección, fomento y/o tolerancia asociadas a la obtención de los mismos en época estival. La presencia de granos sin embrión y embriones sueltos de la familia Amaranthaceae y de granos probablemente hervidos de Zea mays indican que también fueron parte de los alimentos consumidos, y que Zea mays podría haber sido una de las plantas cultivadas en las terrazas de EC2. Particularmente, las especies de Amaranthaceae en estos contextos aparecen bajo una asociación semejante de diversos granos de Chenopodium quinoa, Chenopodium y/o Amaranthus. Por el contrario, en EC1.R13 las prácticas vinculadas con el consumo de plantas habrían sido más intensas, teniendo en cuenta la densidad en la que aparecen representadas (36,2 carporrestos/litro), pero homogéneas. La presencia casi única de la familia Amaranthaceae, con marcas de procesamiento por hervido, en estrecha asociación con Cucurbita sp. en el fogón nos permite pensar que fueron parte de los alimentos consumidos. A diferencia de MF.A y EC2.R2, aquí las especies de la familia Amaranthaceae aparecen bajo una asociación de granos muy semejantes entre sí, correspondiendo casi en su totalidad a Chenopodium quinoa.

Los resultados muestran patrones que no se reducen a una sola temporalidad, a la vez que exhiben cambios y continuidades a lo largo del tiempo. En los contextos analizados que presentan ocupaciones desde el primer milenio d.C., con evidencias de ocupación continua o reocupaciones durante el segundo milenio d.C., se habrían aprovechado una mayor diversidad de plantas que habrían requerido diversas prácticas de manejo y obtención. Por otro lado, en el contexto que presenta ocupación desde el segundo milenio d.C. se habrían consumido una menor diversidad de plantas. Las semejanzas de MF con EC2 y con lo conocido para el primer milenio d.C., en lugar de su contemporáneo EC1, podrían estar indicando espacios en los que fue posible recrear prácticas pasadas como el consumo de Trichocereus y de diversos granos de Amaranthaceae. EC1 se aleja notoriamente de ambos contextos y de lo conocido para el primer milenio d.C. pudiendo estos cambios en los alimentos consumidos estar asociados a las transformaciones sociopolíticas del segundo milenio d.C. (Tarragó, 2000). En este sentido, los cambios y continuidades, principalmente en los alimentos consumidos, indicarían una diversidad de contextos al interior del segundo milenio d.C. Hay espacios, como MF.A, que permiten recrear prácticas pasadas llevadas a cabo durante el segundo milenio d.C. (consumo de Trichocereus, diversas Amaranthaceae). Por otra parte, de manera contemporánea, en EC1. R13 se registra un predominio marcado de Chenopodium quinoa.

El predominio de Amaranthaceae en todos los contextos analizados atraviesa el tiempo y el espacio, pudiendo representar continuidades aún en las nuevas trayectorias registradas en EC1. De este modo, se suma a la ocupación de las viviendas sobre sectores altos de la sierra, lo que de acuerdo con Coll Moritan (2018a) reflejaría en EC1 y MF la combinación de lo sagrado-defensivo-productivo en un mismo espacio residencial monumentalizado. Futuras investigaciones, particularmente en sitios de transición entre el primer y segundo milenio d.C., como Morro de Las Espinillas en el valle de Santa María (Scattolin, 2003) y Molinos I en el valle Calchaquí (Baldini, 1992), podrán ayudar a dilucidar el camino de los resultados e ideas aquí esbozadas. 


\section{AGRADECIMIENTOS}

A Javier Nastri y Julieta Lynch quienes dirigieron la Tesis de Doctorado en la cual se desarrolló el presente estudio. A Laura López, Laura Ciampagna y Aylen Capparelli, del Laboratorio 129 (FCNyM, UNLP), por el apoyo en los análisis de macro y microrrestos vegetales. A Natalia Petrucci y Sofía Fernández Sancha por sus útiles sugerencias en el transcurso de los análisis. A Ana María Arambarri por las consultas sobre la identificación de las semillas. A quienes participaron de las campañas arqueológicas de EC1, EC2 y MF. Finalmente, a Don Manuel y Doña Ercilia y a la escuela Cnel. Murga del Carmen por la hospitalidad brindada en Tucumán. Este trabajo fue posible gracias a las becas doctorales de la Universidad Nacional de La Plata y al financiamiento del Proyecto PICT 2015-1941 dirigido por Javier Nastri.

\section{BIBLIOGRAFÍA}

Abiusso, N.G. \& J. Cámara Hernández. 1974. Los maíces autóctonos de la Quebrada de Humahuaca (Jujuy, Argentina). Sus niveles nitrogenados y su composición en aminoácidos. Revista de la Facultad de Agronomía (Tercera Época) 1: 1-25.

Arreguez, G; J. Martínez, N. Oliszewski \& G. Ponessa. 2015. La problemática de recuperación de macrorrestos arqueobotánicos de tamaño pequeño. El caso de las amarantáceas/quenopodiáceas en sitios arqueológicos bajo reparo del Holoceno Medio y Tardío del Noroeste Argentino, en C. Belmar \& V. Lema (eds.), Avances y desafios metodológicos en arqueobotánica. Miradas consensuadas y diálogos compartidos desde Sudamérica, pp. 9-71. Santiago de Chile: Universidad SEK.

Baldini, L. 1992. La transición entre el Formativo Medio y los Desarrollos Regionales en el Area Valliserrana del N.O.A. Contribución Arqueológica 4: 26-35.

Bozarth, S. R. 1987. Diagnostic opal phytoliths from rinds of selected Cucurbita species. American Antiquity 52 (3): 607-615.

Bozarth, S. R. 1993. Maize (Zea mays) cob phytoliths from a Central Kansas Great Bend aspect archaeological site. Plains Anthropologist 38 (146): 279-286.

Bronk Ramsey, C. 2017. Métodos para resumir conjuntos de datos de radiocarbono. Radiocarbono 59 (2): 1809-1833.

Bruno, M. C. \& W. T. Whitehead. 2003. Chenopodium Cultivation and Formative Period
Agriculture at Chiripa, Bolivia. Latin American Antiquity 14 (3): 339-355.

Burkart, A. E. 1949. La posición sistemática del chañar y las especies del género Geoffroea [Leguminosae Dalbergieae]. Darwiniana 9 (1): 9-23.

Burkart, A. E. 1976. A Monograph of the Genus Prosopis (Leguminosae, subfam. Mimosoideae). Journal Arnold Arboretum 57 (3-4): 219-249 y 450-530.

Cano, S. F. 2011. Utilización de Recursos Vegetales y Subsistencia en el Valle de Santa María durante el Período de Desarrollos Regionales: Un Caso de Estudio en el Sitio El Pichao (S Tuc Tav 5). Tesis de Licenciatura, Universidad Nacional de Tucumán, Argentina.

Cantarelli, V. 2019. Dos quebradas, un poblado. La organización espacial de El Carmen 1, sierra del Cajón, provincia de Tucumán (Argentina). Boletín de Antropología Universidad de Antioquia 34 (57): 15-44.

Capparelli, A. 2008. Caracterización cuantitativa de productos intermedios y residuos derivados de alimentos del algarrobo (Prosopis flexuosa y P. chilensis, Fabaceae): aproximación experimental aplicada a restos arqueobotánicos desecados. Darwiniana 46 (2): 175-201.

Casas, A. 2001. Silvicultura y domesticación de plantas en Mesoamérica, en B. Rendón Aguilar, S. Rebollar Domínguez, J. Caballero Nieto \& M. A. Martínez Alfaro (eds.), Plantas, cultura y sociedad. Estudio sobre la relación entre seres humanos y plantas en los albores del siglo XXI, pp. 123-158. México, Universidad Autónoma Metropolitana, Secretaría del Medio Ambiente, Recursos Naturales y Pesca.

Coll Moritan, V. 2017. Uso y manejo del espacio habitacional durante el período Intermedio Tardío en el centro-oeste del valle de Santa María (Catamarca-Tucumán). Tesis Doctoral, Universidad de Buenos Aires, Argentina.

Coll Moritan, V. 2018a. The Monumentalization of Dwelling Spaces in West-Central Santa María Valley During the Late Intermediate Period (AD 1000-1450), Northwest Argentina, en A. Álvarez Larrain \& C. Greco (eds.), Political Landscapes of the Late Intermediate Period in the Southern Andes. The Pukaras and Their Hinterlands. pp. 95-129. Suiza: Springer.

Coll Moritan, V. 2018b. Análisis espacial del registro arquitectónico en dos poblados del valle de Santa María (Catamarca-Tucumán). Relaciones de la Sociedad Argentina de Antropología 43 (2): 159-183.

Coll Moritan, V.; V. Cantarelli \& J. Nastri. 2015. El Carmen 1, un poblado Intermedio Tardío en el valle de Santa María (Prov. de Tucumán). Revista del Museo de Antropología 8 (1): 105-114. 
Coll Moritan, V. \& J. Nastri. 2015. Organización social y asentamientos Intermedio Tardíos en el Valle de Santa María: problemas y vías de análisis. Arqueología 21 Dossier: 67-87.

García, M. \& M. Uribe. 2012. Contextos de uso de las plantas vinculadas al Complejo Pica Tarapacá, Andes Centro-Sur: arqueobotánica y agricultura en el período Intermedio Tardío (ca. 1250-1450 DC). Estudios Atacameños 44: 107-122.

Hastorf, C. A. \& M. F. Wright, 1998. Interpreting wild seeds from archaeological sites, a dung charring experiment from the andes. Joumal of Ethnobiology 18 (2): 211-227.

Hogg, A.; Q. Hua, P. G. Blackwell, C. E. Buck, T. P. Guilderson. T. J. Heaton, M. Niu, J. G. Palmer, P. J. Reimer, R. W. Reimer, C. Turney \& S. Zimmerman. 2013. HCAL13 Southern Hemisphere calibration, 0-50,000 years cal BP. Radiocarbon 55 (4): 1889-1903.

Kiesling, R. 1978. El género Trichocereus (Cactaceae): I: Las especies de la República Argentina. Darwiniana 21 (2-4): 263-330.

Korstanje, M. A. \& M. P. Babot. 2007. A microfossil characterization from South Andean economic plants, en M. Madella \& D. Zurro (eds.), Plants, People and Places: Recent Studies in Phytholith Analysis, pp. 41-72. Oxbow Books, Oxford.

Lema, V. 2009. Domesticación vegetal y grados de dependencia ser humano- planta en el desarrollo cultural prehispánico del noroeste argentino. Tesis Doctoral, Universidad Nacional de La Plata, Argentina.

Lema, V. 2014. Boceto para un esquema: domesticación y agricultura temprana en el Noroeste argentino. Revista Española de Antropología Americana 44 (2): 465-494.

Lema, V.; D. Andreoni, A. Capparelli, G. Ortiz, R. Spano, M. Quesada \& F. Zorzi. 2015. Protocolos y avances en el estudio de residuos de pipas arqueológicas de Argentina. Aportes para el entendimiento de metodologías actuales y prácticas pasadas. Estudios Atacameños 1 (51): 77-97.

Lema, V.; A. Capparelli \& M. L. Pochettino. 2008. Taxonomic identification of dry and carbonized archaeobotanical remains of Cucurbita species through seed coat micromorphology. Vegetation History and Archaeobotany 17 (Suppl 1): S277-S286.

Longo, A. 2020. Prácticas cotidianas durante el primer y segundo milenio d.C. en el sector centro-occidental del valle de Santa María (Catamarca-Tucumán). Tesis Doctoral, Universidad Nacional de La Plata, Argentina.

Longo, A. \& J. Nastri. 2018. Análisis exploratorio de la variabilidad de la cerámica de superficie en el sitio El Carmen 2 (valle de Santa María, Tucumán). Arqueología 24 (2): 87-108.
López, M. L.; M.C. Bruno \& M.T. Planella. 2015. El género Chenopodium: metodología aplicada a la identificación taxonómica en ejemplares arqueológicos. Presentación de casos de estudio de la región surandina, en C. Belmar \& V. Lema (eds.), Avances y desafios metodológicos en arqueobotánica. Miradas consensuadas y diálogos compartidos desde Sudamérica, pp. 89-121. Santiago de Chile: Universidad SEK.

Madella, M.; A. Alexandre \& T. Ball. 2005. International Code for Phytolith Nomenclature 1.0. Annals of Botany 96: 253-260.

McRostie, V. 2014. Arboricultura y silvopastoralismo en el Período Formativo (1400 a.C.-500 d.C.) de la cuenca del Salar de Atacama. Chungara 46 (4): 543-557.

Miller, N. 1988. Ratios in Paleoethnobotanical analysis, en C. A. Hastorf \& V. S. Popper (eds.), Current Paleoetnobotany. Analytical Methods and Cultural Interpretations of Archaeological Plant Remains, pp. 72-85. Chicago: University of Chicago.

Muñoz-Schick, M. 1995. Revisión del género Cristaria (Malvaceae) en Chile. Boletín del Museo Nacional de Historia Natural de Chile 45: 45-110.

Nastri, J. 1997-1998. Patrones de asentamiento prehispánicos tardíos en el sudoeste del valle de Santa María (Noroeste argentino). Relaciones de la Sociedad Argentina de Antropología XXII-XXIII: 247-270.

Nastri, J.; V. Coll Moritan \& C. Belloti López de Medina. 2012. El Intermedio Tardío en la Sierra del Cajón (Catamarca). Avance de las investigaciones en Morro del Fraile. Estudios sociales del NOA 12: 81-110.

Nastri, J.; G. Pratolongo, A. Reynoso \& A. M. Vargas. 2009. Arqueología en la Sierra del Cajón: poblados, corrales y pinturas, en A. Austral \& M. Tamagnini (eds.). Problemáticas de la Arqueología Contemporánea, tomo 3, pp. 715-728. Río Cuarto: Universidad Nacional de Río Cuarto.

Nastri, J.; F. Schaefers \& V. Coll Moritan. 2010. Deconstruyendo la secuencia agroalfarera del NOA. Del Medio al Intermedio Tardío en Morro del Fraile, Sierra del Cajón (Provincia de Catamarca), en J. R. Bárcena \& H. Chiavazza (eds.). Arqueología Argentina en el Bicentenario de la Revolución de Mayo, tomo 3, pp. 1161-1167. Mendoza: ConicetIncihusa.

Oliszewski, N. 1997. Metodología para la recuperación de especímenes arqueobotánicos. El caso del Campo del Pucará. Actas del XII Congreso Nacional de Arqueología Argentina, tomo 3: 327-335. Universidad Nacional de La Plata, La Plata.

Pagán Jiménez, J. R. 2015. Almidones, Guía de material comparativo moderno del Ecuador para los estudios paleoetnobotánicos en el neotrópico. Buenos Aires: Aspha. 
Patterer, N. I.; E. Passeggi \& A. F. Zucol. 2011. Análisis fitolíticos de suelos del sudoeste de la Provincia de Entre Ríos (Argentina) como una herramienta para comprender sus procesos pedológicos. Revista Mexicana de Ciencias. Geológicas 28 (1): 132-146.

Pazzarelli, F. 2011. Arqueología de la comida. Cultura material $y$ prácticas de alimentación en Ambato, Catamarca (Argentina) siglos $V-X I$. Tesis Doctoral, Universidad Nacional de Córdoba, Argentina.

Parodi, L. R. 1959. Enciclopedia argentina de agricultura y jardinería. ACME, Buenos Aires, tomo 1, 1er. vol.

Pearsall, D. M. 2016. Paleoethnobotany. A Handbook of Procedures. Third Edition. London and New York: Routledge.

Petrucci, N. 2017. Complejidad social y diversidad biocultural en el valle de Yocavil: mil quinientos años de interacciones entre comunidades humanas y poblaciones vegetales. Tesis Doctoral, Universidad Nacional de La Plata, Argentina.

Petrucci, N. \& V. Lema. 2016. Primeras aproximaciones a la identificación de técnicas de procesamiento en carporrestos de Zea mays L.: detección de granos hervidos en restos arqueobotánicos secos y carbonizados. Intersecciones en Antropología 17: 291-302.

Petrucci, N.; V. Lema, M. L. Pochettino, V. Palamarczuk, R. Spano \& M. Tarragó. 2018. From weeds to wheat: a diachronic approach to ancient biocultural diversity in the Santa María valley, northwest Argentina. Vegetation History and Archaeobotany 27(1): 229-239.

Petrucci, N. \& R. Spano. 2019. Arqueobotánica del sitio temprano Soria 2 (Catamarca, Argentina). Boletín de la Sociedad Argentina de Botánica 54: 137-154.

Petrucci, N. \& M. Tarragó. 2015. Restos arqueobotánicos del sitio Rincón Chico 1. Una aproximación a los posibles escenarios de procesamiento, uso y consumo. Comechingonia 19(1): 67-86.

Petrucci, N. \& M. Tarragó. 2019. Restos arqueobotánicos del montículo oriental de Rincón Chico 15, Catamarca. Prácticas de consumo y aprovisionamiento. Intersecciones en Antropología 20(1): 25-37.

Piperno, D. \& D. Pearsall. 1993. Phytoliths in the reproductive structures of maize and teosinte: implications for the study of maize evolution. Journal of Archaeological Science 20: 337-362.

Planchuelo, A. M. 1975. Estudio de los frutos y semillas del género Chenopodium en la Argentina. Darwiniana 19: 528-565.
Pochettino, M. L. \& M. C. Scattolin. 1991. Identificación y significado de frutos y semillas carbonizados de sitios arqueológicos de la ladera occidental del Aconquija, Prov. Catamarca, Rca. Argentina. Revista Museo La Plata, Antropología 9: 169-181.

Popper, V. S. 1988. Selecting Quantitative Measurements in Paleoetnobotany, en C. Hastorf \& V. Popper (eds.), Current Paleoetnobotany. Analytical Methods and Cultural Interpretations of Archaeological Plant Remains, pp. 53-71. Chicago: The University of Chicago Press.

Pozner, R. 2010. Cucurbitaceae Juss., nom. cons. en L. J. Novara (ed.), Flora del Valle de Lerma (Provincia de Salta, República Argentina). Aportes Botánicos de Salta, Serie Flora 9(8): 1-57. Facultad de Ciencias Naturales, Universidad Nacional de Salta.

Ruiz Huidobro, O. J. 1972. Descripción geológica de la hoja 11e, Santa María. Buenos Aires: Servicio Nacional Minero Geológico.

Scattolin, M. C. 2003. Recursos arquitectónicos y estilos cerámicos en los siglos IX y X d.C. en el valle de Santa María (Catamarca, Argentina), en P. Cornell \& P. Stenborg (eds.), Local, regional, global: prehistoria, protohistoria e historia en los Valles Calchaquies. Etnologiska Studier 46: 63-101. Gotemburgo.

Scattolin, M. C. 2006. De las comunidades aldeanas a los curacazgos en el Noroeste Argentino. Boletín de Arqueología PUCP 10: 357-398.

Tarragó, M. 2000. Chakras y pukaras. Desarrollos sociales tardíos. Los pueblos originarios y la conquista, en $\mathrm{M}$. Tarragó (ed.), Nueva Historia Argentina vol. 1, pp. 257-300. Buenos Aires: Editorial Sudamericana.

Tarragó, M. 2011. Poblados tipo pukara en Yocavil. El plano de Rincón Chico 1 (Catamarca, Argentina). Estudios Sociales del NOA, nueva serie, 11: 33-61.

Trópicos.org. Missouri Botanical Garden. 2021, http://www. tropicos.org

Villagrán, C.; V. Castro, G. Sánchez, M. Romo, C. Latorre \& L. F. Hinojosa. 1998. La tradición surandina del desierto: Etnobotánica del área del Salar de Atacama (Provincia de ElLoa, Región de Antofagasta, Chile). Estudios Atacameños 16: 7-105.

Zuloaga, F. O.; M. J. Belgrano \& C. A. Zanotti. 2019. Actualización del Catálogo de las Plantas Vasculares del Cono Sur. Darwiniana, nueva serie 7(2): 208-278. DOI: https://doi.org/10.14522/darwiniana.2019.72.861 [permanentemente actualizado, consulta 2021]: http://www. darwin.edu.ar/proyectos/floraargentina/fa.htm 